\title{
Pentobarbital and picrotoxin have reciprocal actions on single $\mathrm{GABA}_{\mathrm{A}}$ receptor channels
}

\author{
Roy E. Twyman, Carl J. Rogers and Robert L. Macdonald \\ Department of Neurology, University of Michigan Medical Center, Ann Arbor, MI 48104 (U.S.A.)
}

(Received 26 April 1988; Revised version received 26 August 1988; Accepted 29 August 1988)

Keywords: Pentobarbital; Barbiturate; Picrotoxin; Convulsant; $\gamma$-Aminobutyric acid; Single chloride channel; Patch clamp

Pentobarbital (PB) and picrotoxin (PIC) bind to allosterically coupled sites on the $\mathrm{GABA}_{\mathrm{A}}$ receptor complex but have opposite effects on GABA receptor currents. $\mathrm{PB}$, an anesthetic/anticonvulsant, enhances, and PIC, a convulsant, inhibits GABA receptor currents. PB and PIC also had opposite effects on single main conductance channel GABA receptor currents recorded from excised outside-out patches from mouse spinal neurons in culture. PB prolonged bursts of channel openings by increasing mean duration and number of intraburst openings. PIC shortened bursts by reducing mean duration and number of intraburst openings. The results demonstrate the reciprocal regulation of GABA receptor channels by PB and PIC and suggest that their allosterically coupled binding sites are coupled to the chloride channel in an opposite manner.

The $\gamma$-aminobutyric acid $\left(\mathrm{GABA}_{\mathrm{A}}\right)$ receptor chloride channel has been shown to be an oligomeric complex with binding sites for GABA, benzodiazepines $/ \beta$-carbolines, picrotoxin (PIC)-like drugs and barbiturates such as pentobarbital (PB) [12]. PB and PIC bind to distinct, but allosterically coupled, sites independent of the GABA binding site $[9,19]$. $\mathrm{PB}$, an anesthetic and anticonvulsant drug, potentiates GABA-mediated inhibition [8, 11], whereas PIC, a convulsant drug, reduces GABAmediated inhibition $[7,18]$. The basis for the opposite actions of PB and PIC is uncertain. We have used the outside-out [5] patch clamp technique [17] to study the modification by PB and PIC of GABA receptor single channel currents obtained from mouse spinal cord neurons grown in cell culture [15].

Prior to use in experiments, mouse spinal cord neurons were grown in dissociated cell culture for 2-5 weeks according to methods previously described [15]. At the time of experiment, culture medium was replaced with a HEPES-buffered salt solution containing the following (in $\mathrm{mM}$ ): $\mathrm{NaCl} \mathrm{142,} \mathrm{KCl} 8.09, \mathrm{CaCl}_{2} 1, \mathrm{MgCl}_{2} 6$, glucose 10 , Na-HEPES 10 (pH 7.4). Recording pipettes were filled with a symmetrical chlor-

Correspondence: R.L. Macdonald, Neuroscience Laboratory Building, 1103 E. Huron Street, Ann Arbor, MI 48104-1687, U.S.A. 
ide salt solution containing (in $\mathrm{mM}$ ): $\mathrm{KCl} 153, \mathrm{MgCl}_{2}$ 1, Na-HEPES 10, EGTA 5, $\mathrm{NaOH} 1, \mathrm{KOH} 2$ (pH 7.38). All solutions contained the specific glycine antagonist strychnine (Sigma, St. Louis, MO, U.S.A.) at a concentration of $200 \mathrm{nM}$. Experiments were performed at room temperature $\left(21-23^{\circ} \mathrm{C}\right)$ using a Model L/M EPC-7 (List Medical Instruments, Duderstadt, F.R.G.) amplifier and recorded on a video data recording system (14 bit, $40 \mathrm{kHz}$ bandwidth). Data were later digitized ( $8 \mathrm{kHz}$ sampling rate, $1 \mathrm{kHz}$ low-pass 8-pole Bessel filter) and analyzed by computer using a locally modified single channel detection program (IPROC-2, M. Sloderbeck and C.J. Lingle, Florida State University, FL, U.S.A.) and a locally written program. GABA and GABA with PB or PIC were dissolved in the bath solution and applied by pressure ejection from blunt tip micropipettes within $50 \mu \mathrm{m}$ of the membrane. Whole cell and outsite-out patch recordings were obtained using a method similar to Hamill et al. [5]. To compare the effects of drugs on the GABA receptor single channel openings, data were analyzed by calculating mean open, closed, and burst duration and openings per burst (defined later) per drug application and evaluating the results by one-tailed Student's $t$-test for independent groups. Data are presented in the form of mean \pm S.E.M. unless otherwise specified.

Whole cell recordings were used to establish concentrations of PB and PIC to produce quantitatively similar but opposite effects on the magnitude of the GABA current response. Low concentrations of GABA and PB were selected to reduce the possible effect of desensitization. Higher concentrations of PIC produced so little current to make analyses more difficult. At a concentration of $50 \mu \mathrm{M}, \mathrm{PB}$ enhanced the
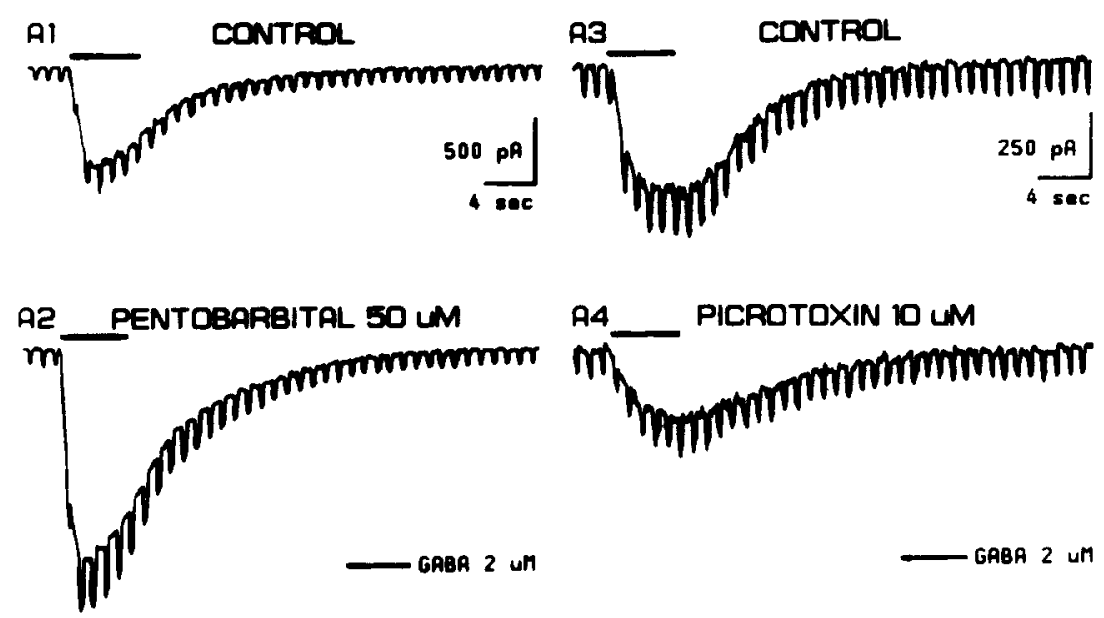

Fig. 1. Whole-cell and single-channel responses evoked by GABA $(2 \mu \mathrm{M})$ alone and in the presence of PB $(50 \mu \mathrm{M})$ or PIC (10 $\mu \mathrm{M})$. A: whole cell recordings were obtained from spinal cord neurons. GABA evoked inward (down going) currents with associated conductance increases (increased amplitude of short duration (200 ms) voltage pulses applied at $1 \mathrm{~s}$ intervals) (Al, A3). In the presence of pentobarbital (PB). GABA-evoked current was increased (A2). In the presence of PIC, GABA-evoked current was reduced (A4). The changes in GABA-receptor currents were reversible (not illustrated). B: single-channel recordings were obtained from outside-out patches. Prior to GABA application, rare brief openings occurred 
GABA current $122 \pm 6 \%$ (16 trials, 5 neurons) (Fig. 1A1, 2) whereas $10 \mu \mathrm{M}$ PIC reduced the current $75 \pm 2 \%$ ( 7 trials, 3 neurons) Fig. 1A3, 4).

Outside-out patches were obtained from spinal cord neuron somata. Single channel recordings were made with the patches voltage-clamped at the potassium equilibrium potential (intrapipette potential $-75 \mathrm{mV}$ ). Prior to addition of GABA, rare, brief inward currents were recorded (Fig. 1B1). GABA $(2 \mu \mathrm{M})$ evoked single and bursting inward chloride currents in 80 of 100 patches (Fig. 1B2). Only those patches with reproducible responses were used in these analyses. Openings with at least 2 different current amplitudes were recorded, representing 2 different conductance states (approx. 27 and $18 \mathrm{pA}$ ) (not illustrated). The larger, main conductance state occurred more frequently ( $89 \%$ of detected openings) and was used in these analyses. Openings to the subconductance state generally were briefer and technically more difficult to accurately resolve. Dwell times less than twice the system dead time (dead time $=130$ $\mu \mathrm{s})$ could not be reliably estimated and were counted as unresolved openings or closings. Currents were increased by PB (Fig. 1B3) and reduced by PIC (Fig. 1B4). The magnitude of the conductance states were $26.7 \pm 1.1 \mathrm{pS}$ and $17.7 \pm 0.6 \mathrm{pS}$ (mean \pm S.D.) ( 80 patches). The conductances were not altered by either PB $(26.2 \pm 0.5$ and $17.7 \pm 0.8 \mathrm{pS}, 15$ patches) or PIC $(26.8 \pm 1.2$ and $17.5 \pm 0.7 \mathrm{pS}, 24$ patches). Since neither PB nor PIC altered conductance magnitude, we determined the effects of PB and PIC on the temporal characteristics of GABA receptor currents.

To reduce the effects of desensitization, drug applications were limited to $20 \mathrm{~s}$. To obtain kinetic stationarity during a constant drug concentration at the patch, records

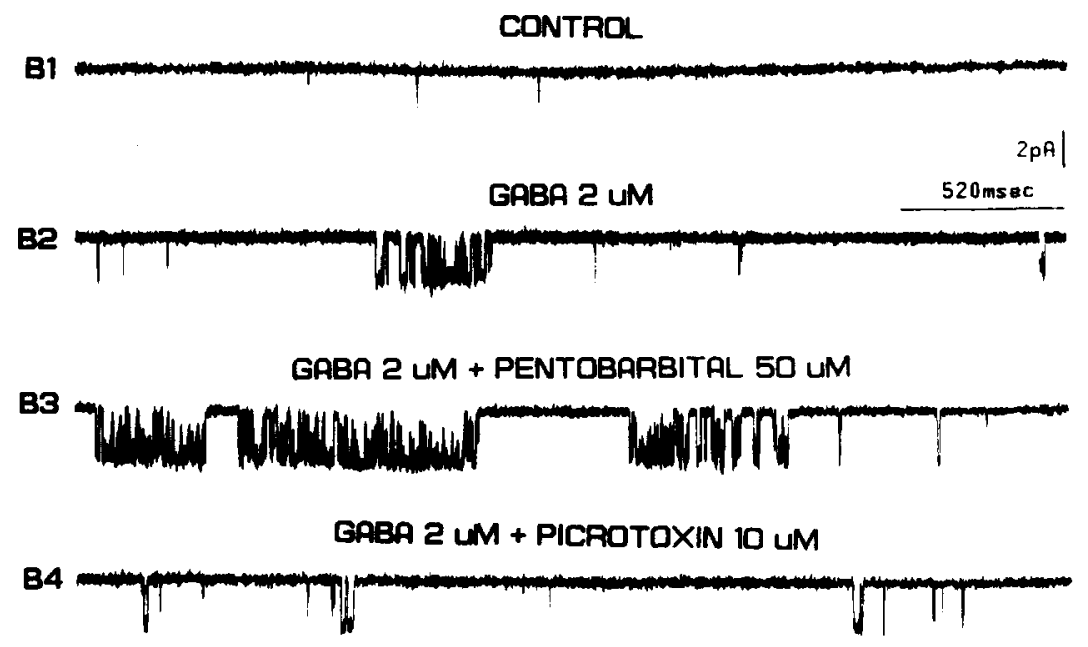

(B1). GABA evoked an increase in channel openings (downward deflections) (B2). In the presence of PB (B3), GABA receptor currents were increased whereas in the presence of PIC (B4), GABA receptor currents were reduced. Neurons and patches were voltage clamped to the potassium equilibrium potential $(-75 \mathrm{mV})$. Pressure pipettes were brought within $50 \mu \mathrm{m}$ of the neuron or patch pipette after ejecting diluted solution distant from the recording site. Ejection pipettes were immediately removed from the bath solution after application. To obtain responses in the presence of PB or PIC, the cell or patch was exposed to the drug using a pressure pipette immediately prior to application of GABA plus drug from a second pipette. 
were analysed from 2 to $17 \mathrm{~s}$ from the first opening. This was confirmed by analysing consecutive $5 \mathrm{~s}$ epocs of the drug application and finding stable kinetic properties.

$P B$ and PIC had reciprocal effects on mean open properties of GABA receptor currents. GABA evoked currents with a mean open time per application of $4.99 \pm 0.24$ ms ( $n=129$ applications). In $\mathrm{PB}(50 \mu \mathrm{M})$, mean open time was significantly increased to $9.73 \pm 0.42 \mathrm{~ms}(n=75$ applications, $P<0.0001)$, while in PIC $(10 \mu \mathrm{M})$, mean open time was reduced to $4.01 \pm 0.33 \mathrm{~ms}(n=89$ applications, $P<0.01)$. GABA evoked $11.6 \pm 1.0$ openings/s. In PB, GABA evoked $13.2 \pm 0.9$ openings/s (N.S.), and in PIC, GABA evoked $1.8 \pm 0.3$ openings $/ \mathrm{s}(P<0.0001)$. With GABA, the channel was open $5.4 \pm 0.46 \%$ of the time. In GABA plus $\mathrm{PB}$, the channel was open a significantly higher percent of time $(13.0 \pm 0.90 \%, P<0.0001)$, and in GABA plus PIC, the channel was open a lower percent of time $(0.75 \pm 0.12 \%, P<0.0001)$. Channel open times and closed times were placed into frequency histograms to show the frequency of occurrence of events with a particular duration. Normalized open duration frequency histograms of all openings were shifted to longer times in the presence of $\mathrm{PB}$ and to shorter times in PIC (Fig. 2A). Closed time distributions of all closings in the range of $0.5-50 \mathrm{~ms}$ were altered little by PB or PIC (Fig. 2B). Thus, PB enhanced GABA receptor current by increasing the mean channel open duration. PIC, however, reduced GABA receptor current by reducing the mean open duration and the frequency of channel opening.

The properties of mean open duration and opening frequency do not characterize how openings may be clustered together in the form of bursts of openings. Both GABA [2, 10-16] and acetylcholine [4] evoke bursts or groups of channel openings, suggesting that bursting activity may be a fundamental behavior of neurotransmitter receptor channels. For analysis, a burst was defined as an opening or a group of openings separated by closures greater than a critical time, $t_{\mathrm{c}}$ [4]. For $2 \mu \mathrm{M}$ GABA, a $t_{\mathrm{c}}$ of $5 \mathrm{~ms}$ was calculated using a modification of the method of equal proportions of misclassified closures [4].

PB and PIC had reciprocal effects on GABA receptor channel bursting properties. GABA evoked a mean burst duration per application of $12.9 \pm 0.81 \mathrm{~ms}$. Bursts were significantly prolonged in $\mathrm{PB}(26.4 \pm 1.4 \mathrm{~ms}, P<0.0001)$ and shortened in PIC $(7.5 \pm 0.77 \mathrm{~ms}, P<0.0001)$. The burst duration frequency distribution of all bursts was shifted to longer durations in PB and to shorter durations in PIC (Fig. 2C). The mean number of openings per burst per application of GABA was $2.01 \pm 0.07$. Openings per burst were significantly increased by $\mathrm{PB}(2.39 \pm 0.10, P<0.01)$ and reduced by PIC $(1.55 \pm 0.07, P<0.0001)$ (Fig. 2D). The mean intraburst closed time per application for GABA was $1.52 \pm 0.04 \mathrm{~ms}$. The mean intraburst closed time was unchanged by PB $(1.55 \pm 0.04 \mathrm{~ms}$, N.S. $)$ or by PIC $(1.61 \pm 0.06 \mathrm{~ms}$, N.S. $)$.

Prolongation of bursts by $\mathrm{PB}$ could thus be accounted for by two mechanisms: (1) an increase in mean channel open time, and (2) an increase in the mean number of openings per burst. Since the intraburst closed time did not change, this resulted in an increase in current per burst. In contrast, PIC reduced burst duration in a reciprocal fashion by decreasing mean channel open time and in the number of openings per burst resulting in a reduction of current. 

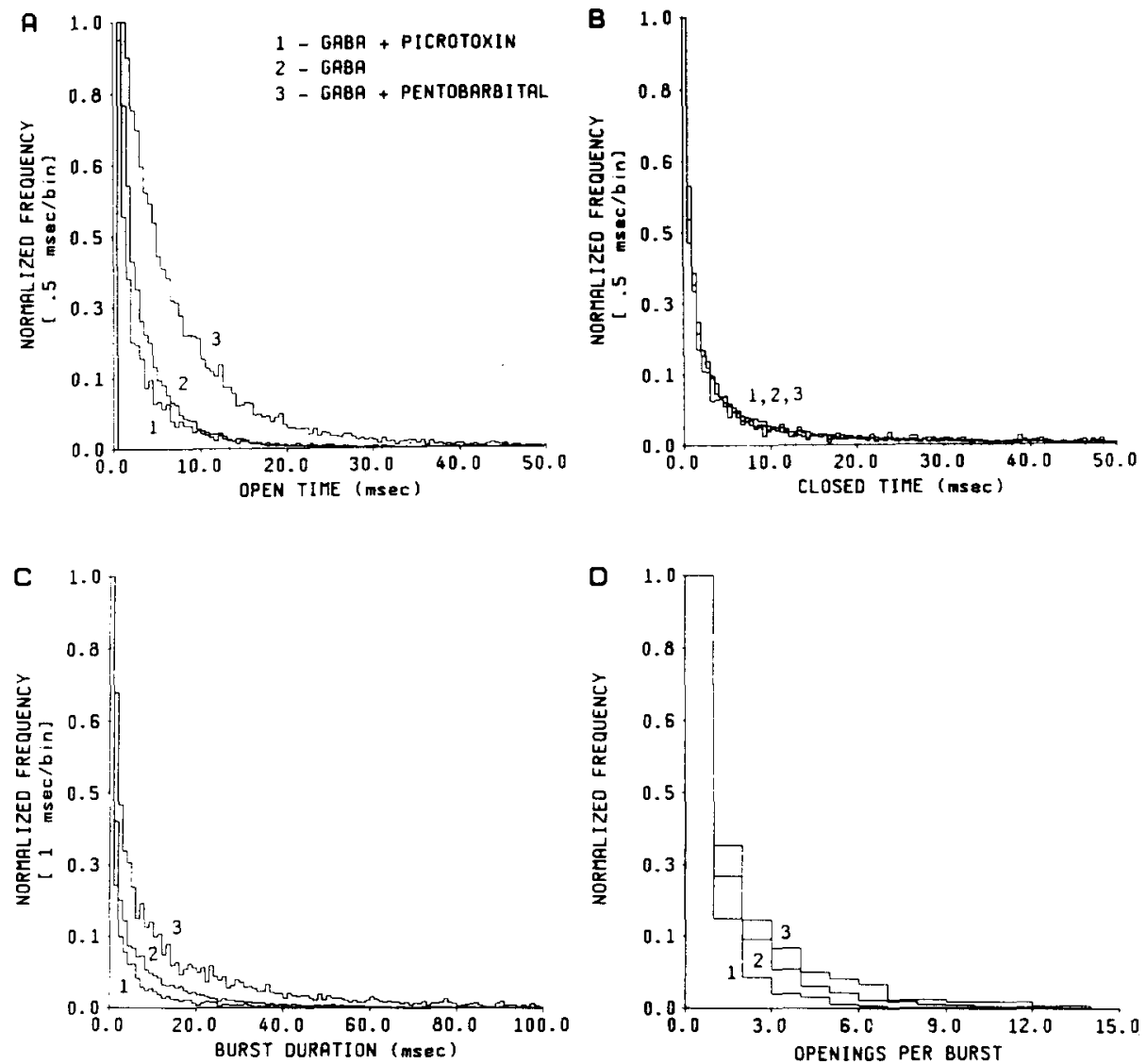

Fig. 2. Normalized open and closed time frequency histograms of currents evoked by GABA alone and in the presence of PB or PIC. A, B: open and closed durations of all openings and closings were collated into bins of $0.5 \mathrm{msec}$ and displayed over a range of $1-50 \mathrm{~ms}$. Closings were distributed over a much wider range (up to seconds) and were not illustrated. In the presence of pentobarbital (PB), the open time distribution was shifted to the right whereas in picrotoxin (PIC) the open distribution was shifted to the left (A). The distribution of short closed times (range $0.5-50.0 \mathrm{~ms}$ ) was unchanged in PB or PIC (B). The data were pooled to collect 32765 openings and 25259 short closures for GABA, 23666 and 19158 respectively for GABA + PB, and 3744 and 2634 respectively for GABA + PIC. C, D: burst durations of all bursts were collated into $1 \mathrm{~ms}$ bins and displayed over a range of 1-100 ms. In the presence of $P B$, the burst duration distribution was shifted to the right whereas in PIC the distribution was shifted to the left (C). The frequency distribution of number of openings per burst was shifted to the right by $\mathrm{PB}$, whereas the distribution was shifted to the left by PIC (D). The data were pooled to collate 16054 bursts for GABA, 9504 bursts for GABA + PB and 2433 bursts for GABA + PIC. All frequency distributions were normalized to display relative distributions.

PB is known to enhance agonist binding to both GABA and benzodiazepine (diazepam) binding sites, whereas PIC does not affect GABA or benzodiazepine binding $[1,3,6,13,14]$. In preliminary studies [20] we have shown that in the presence of diazepam, which binds to a separate benzodiazepine binding site, GABA receptor single channel currents were increased in frequency without an alteration in burst 
structure. These results suggested that agents which primarily produce an increase in GABA affinity produce an increase in the frequency of bursting currents without affecting burst structure. In the present study, PB did not change the frequency of GABA-evoked chloride currents. However, PB and PIC reciprocally altered burst structure.

GABA receptor channel bursting properties were modified in an opposing manner by the two drugs. PB prolonged bursts of openings by increasing mean duration of openings and by increasing the mean number of openings in a burst. In contrast, PIC shortened bursts by reducing mean open time.and reducing the mean number of openings per burst. The results provide evidence for reciprocal modulation of GABA receptor channel gating by ligands that have oppposite effects on central nervous system function. Perhaps the allosterically coupled binding sites for PB and PIC are coupled in an opposing manner to the chloride channel. PB may stabilize the open state of the channel, and thus prolong bursting currents. In contrast, PIC may destabilize the open state, and thus shorten bursting currents.

Single channel studies have indicated that the $\mathrm{GABA}_{\mathrm{A}}$ receptor channel is quite complex $[2,10,16]$ and may have at least 4 conductance levels [3]. The main conductance state of the GABA receptor channel has multiple open and closed states, thus a large number of kinetic models for the ion channel behavior are possible. Analysis of multiple states is beyond the scope of the present paper. Further study is needed to delineate how PB and PIC may modulate the kinetics of the various open and closed states.

We thank Ms. Nancy Fox for her technical assistance in the preparation of cell cultures, and Mrs. Marjorie Mills for her secretarial assistance.

I Asano, T. and Ogasawara, N., Chloride dependent stimulation of GABA and benzodiazepine receptor binding by pentobarbital, Brain Res., 225 (1981) 212-216.

2 Bormann, J. and Clapham, D.E., $\gamma$-Aminobutyric acid receptor channels in adrenal chromaffin cells: a patch clamp study, Proc. Natl. Acad. Sci. U.S.A., 82 (1985) 2168-2172.

3 Bormann, J., Hamill, O.P. and Sakmann, B., Mechanism of anion permeation through channels gated by glycine and $\gamma$-aminobutyric acid in mouse cultured spinal neurones, J. Physiol. (Lond.), 385 (1987) 243-286.

4 Colquhoun, D. and Sakmann, B., Fast events in single-channel currents activated by acetylcholine and its analogues at the frog muscle end-plate, J. Physiol. (Lond.), 369 (1985) 501-557.

5 Hamill, O.P., Marty, A., Neher, E., Sakmann, B. and Sigworth, F.J., Improved patch-clamp techniques for high-resolution current recording from cells and cell-free membrane patches, Pflugers Arch. ges. Physiol., 391 (1981) 85-100.

6 Leeb-Lundberg, F., Snowman, A. and Olsen, R.W., Perturbation of benzodiazepine receptor binding by pyrazolopyridines involves picrotoxin/barbiturate receptor sites, Proc. Natl. Acad. Sci. U.S.A., 77 (1980) 7462-7472.

7 Macdonald, R.L. and Barker, J.L., Specific antagonism of GABA-mediated postsynaptic inhibition in cultured mammalian spinal cord neurons: a common mode of convulsant action, Neurology, 28 (1978) 325-330.

8 Macdonald, R.L. and Barker, J.L., Different actions of anticonvulsant and anesthetic barbiturates revealed by use of cultured mammalian neurons, Science, 200 (1978) 775-777.

9 Maksay, G. and Ticku, M.K., Dissociation of $\left[{ }^{35} S\right] t$-butylbicyclophosphorothionate binding differentiates convulsant and depressant drugs that mediate GABAergic transmission, J. Neurochem., 44 (1984) 480-486. 
10 Martin, R.J., $\gamma$-Aminobutyric acid- and piperazine activated single channel currents from Ascaris suum body muscle, Br. J. Pharmacol., 84 (1985) 445-461.

11 Nicoll, R.A., Pentobarbital action on frog motorneurons, Brain Res., 96 (1975) 119-123.

12 Olsen, R.W., The GABA postsynaptic membrane receptor-ionotophore complex: site of action of convulsant and anticonvulsant drugs, Mol. Cell. Biochem., 39 (1981) 261-279.

13 Olsen, R.W. and Snowman, A.M., Chloride-dependent enhancement by barbiturate of $\gamma$-aminobutyric acid receptors, uptake, release and synthesis in vitro, J. Neurosci., 2 (1982) 1812-1813.

14 Olsen, R.W., Ticku, M.K., VanNess, P.C., and Greenlee, D., Effects of drugs on $\gamma$-aminobutyric acid receptors, uptake, release and synthesis in vitro, Brain Res., 139 (1977) 277-294.

15 Ransom, R.R., Neale, E., Henkart, M., Bullock, P.N. and Nelson, P.G., Mouse spinal cord in cell culture. I. Morphology and intrinsic neuronal electrophysiological properties, J. Neurophysiol., 40 (1977) 1132-1150.

16 Sakmann, B., Hamill, O.P. and Bormann, J., Patch-clamp measurements of elementary chloride currents activated by the putative inhibitory transmitters GABA and glycine in mammalian spinal neurons, J. Neural Transm., Suppl. 18 (1983) 83-95.

17 Sakmann, B. and Neher, E., Single Channel Recording, Plenum, New York, 1983, 503 pp.

18 Takeuchi, A. and Takeuchi, N., A study of the action of picrotoxin on the inhibitory neuromuscular junction of the crayfish, J. Physiol. (Lond.), 205 (1969) 377-391.

19 Trifilletti, R.R., Snowman, A.M. and Snyder, S.H., Barbiturate recognition site on the GABA/benzodiazepine receptor complex is distinct from the picrotoxin/TBPS recognition site, Eur. J. Pharmacol., 106 (1984) 441-447.

20 Twyman, R.E., Rogers, C.J. and Macdonald, R.L., Differential mechanisms for enhancement of GABA by diazepam and phenobarbital: a single channel study, Ann. Neurol., in press. 